\title{
Clinicopathological and prognostic significance of platelet-to- lymphocyte ratio in patients with hepatocellular carcinoma
}

\author{
Wei Song ${ }^{1, *}$, Kai Wang ${ }^{1, *}$, Fu-ping Zhong ${ }^{1}$, You-wen Fan ${ }^{1}$, Lang Peng ${ }^{1}$, Shu-bing \\ Zou ${ }^{1}$ \\ ${ }^{1}$ Department of Hepatobiliary Surgery, The Second Affiliated Hospital of Nanchang University, Nanchang, China \\ *These authors have contributed equally to this work
}

Correspondence to: Shu-bing Zou, email: zousb999@163.com

Keywords: platelet to lymphocyte ratio (PLR), hepatocellular carcinoma, biomarker, prognosis, meta-analysis

Received: September 07, 2016

Accepted: October 17, 2016

Published: November 09, 2016

\section{ABSTRACT}

The platelet-to-lymphocyte ratio (PLR) is reported to be a prognostic factor in multiple malignancies. The aim of this study was to assess its prognostic value in hepatocellular carcinoma (HCC). We performed comprehensive searches of electronic databases for relevant studies. A total of eleven studies comprising 2,507 patients were included. Elevated PLR was significantly associated with poor overall survival (OS) (HR $=1.78 ; 95 \% \mathrm{CI}=1.36-2.34 ; \mathrm{P}<0.001)$ and disease-free survival (DFS)/recurrencefree survival (RFS) $(H R=1.82 ; 95 \% C I=1.56-2.13 ; P<0.001)$. The findings from most subgroup analyses were consistent with those from the overall analysis. In addition, a high PLR correlated with tumor size $>3 \mathrm{~cm}$, TNM stage, lymph node metastasis, distant metastasis, and vascular invasion. We therefore conclude that elevated pretreatment PLR may be predicative of a poor prognosis in patients with HCC.

\section{INTRODUCTION}

Hepatocellular carcinoma (HCC) is the second leading cause of cancer-related death worldwide, with an estimated 500,000 to 1 million deaths per year [1, 2]. More than two-thirds of patients are diagnosed at an advanced stage, when curative treatments, including hepatic resection, radio-frequency ablation, and liver transplantation, are no longer an option [3]. Despite advances in surgical techniques and perioperative management, the overall prognosis of HCC remains poor due to a high recurrence rate and intrahepatic metastasis after curative resection [4]. It is therefore vital to identify novel predictive biomarkers that can be used to improve prognosis and select appropriate therapeutic strategies.

Systemic inflammatory responses play a critical role in the pathogenesis and progression of cancer [5]. Inflammation indicators, such as serum ferritin (SF), neutrophil-to-lymphocyte ratio (NLR), lymphocyteto-monocyte ratio (LMR), platelet-to-lymphocyte ratio (PLR), and C-reactive protein (CRP) have been identified as prognostic indicators in various cancers [6-10]. Studies have also shown that platelets play multiple roles during inflammatory response processes. High platelet counts can promote cancer progression by facilitating neoangiogenesis, production of adhesion molecules and increases in early metastatic niches [11, 12]. By contrast, lymphocytes hinder malignant progression through tumoral infiltration by multiple lymphocyte subtypes. Low lymphocyte counts are often seen in patients with advanced cancer [13]. Moreover, a high platelet-to-lymphocyte ratio (PLR), which is defined as absolute platelet counts divided by lymphocyte counts, is reportedly linked to an unfavorable prognosis in multiple malignancies [10, 14, 15].

Nevertheless, the prognostic value of PLR in HCC has not yet been fully elucidated. Furthermore, there has been no systematic review or meta-analysis to determine the reliability and degree of its prognostic value. We therefore conducted a meta-analysis to assess the effects of pretreatment PLR on OS and DFS/RFS as well as the associations between PLR and the clinicopathological features of patients with HCC.

\section{RESULTS}

\section{Study characteristics}

The literature search of electronic databases identified a total of 186 articles. After duplicates removal, 
115 articles were screened for eligibility. Of these, 95 were excluded through titles and abstracts, leaving 20 articles for detailed evaluation. Nine studies did not meet the inclusion criteria and were therefore excluded. Ultimately, 11 eligible studies, comprising a total of 2,507 patients, were considered eligible for the meta-analysis [16-26]. The PRISMA flow diagram of the study selection process was shown in Figure 1.

Of 11 studies, 10 studies were published in 2015 or later. Eight studies were from China, one from UK, one from USA, and one from Singapore. The sample sizes ranged from 116 to 414 . Ten studies investigated the prognostic role of PLR in OS, and 5 studies explored the prognostic impact of PLR in DFS/RFS. The cut-off values for PLR ranged from 87.87 to 290,4 studies used a PLR cut-off value $\geq 150$, while 7 studies used a PLR < 150. HRs and $95 \%$ CIs were extracted directly from the 9 studies. HRs in 2 studies were estimated by Kaplan-Meier survival curves. Characteristics of included studies are shown in Table 1.

\section{Quality assessment}

In methodological quality of studies, the global quality score ranged $50.0 \%$ to $70.0 \%$, with a median of
$67.6 \%$ (Table 2 ). The subscore of laboratory methodology had the lowest value, with a median quality score of 5.8 out of 14. The most poorly described items were the blinding evaluation, tissue sample conservation, and description of the revelation test procedure.

\section{Meta-analysis}

\section{Overall survival}

Ten studies involving 2,093 patients investigated the association between PLR and OS. Elevated PLR was significantly associated with poor $\mathrm{OS}(\mathrm{HR}=1.78$; $95 \% \mathrm{CI}=1.36-2.34 ; \mathrm{P}<0.001$; Figure 2$)$. The test for heterogeneity was significant, thus, the random-effects model was used $\left(\mathrm{I}^{2}=89 \% ; \mathrm{P}<0.001\right)$. To detect the potential heterogeneity, subgroup analyses stratified by ethnicity, treatment, sample size, disease stage, HR estimation, analysis method, ELCWP score, and the cut-off value of PLR (Table 3). Exploratory subgroup analysis according to ethnicity showed that elevated PLR had more significantly prognostic value for OS in Asian populations $(\mathrm{HR}=1.88 ; 95 \% \mathrm{CI}=1.33-2.65 ; \mathrm{P}<0.001)$. Pooled HRs for OS stratified by treatment, the negative effect of elevated PLR on OS was observed in patients
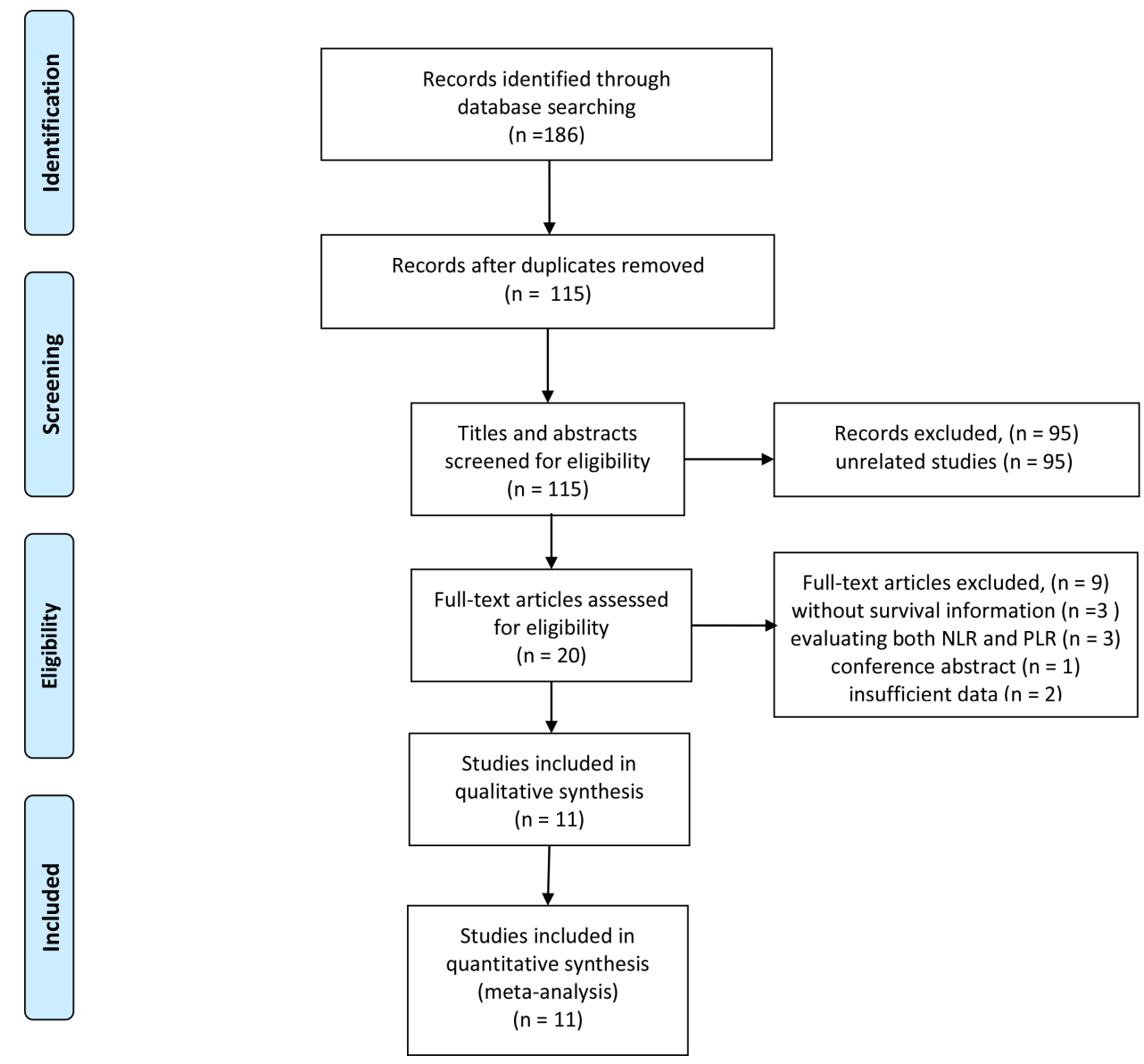

Figure 1: Flow diagram of the study selection process. 
Table 1: Characteristics of the studies included in the meta-analysis

\begin{tabular}{|c|c|c|c|c|c|c|c|c|c|c|c|c|c|c|}
\hline Author & Year & Country & Age (years) & $\begin{array}{c}\text { Study } \\
\text { type }\end{array}$ & $\begin{array}{c}\text { Gender } \\
(\mathbf{M} / \mathbf{F})\end{array}$ & Ethnicity & $\begin{array}{c}\text { Follow-up } \\
\text { (months) }\end{array}$ & Treatment & $\begin{array}{c}\text { No. of } \\
\text { patients }\end{array}$ & Stage & $\begin{array}{c}\text { Cut-off } \\
\text { value }\end{array}$ & $\begin{array}{c}\text { Survival } \\
\text { analysis }\end{array}$ & $\begin{array}{c}\text { HR } \\
\text { estimate }\end{array}$ & Analysis \\
\hline D’Emic & 2016 & USA & $60(28-85)$ & $\mathrm{R}$ & $52 / 64$ & Caucasian & $12(5.3-18.1)$ & Mixed & 116 & Mixed & 290 & OS/PFS & Reported & $\mathrm{MV} / \mathrm{UV}$ \\
\hline Fan & 2015 & China & $49(23-75)$ & $\mathrm{R}$ & $87 / 45$ & Asian & $11(4-46)$ & Chemotherapy & 132 & $\begin{array}{c}\text { Non- } \\
\text { metastatic }\end{array}$ & 137 & OS & Reported & $\mathrm{MV} / \mathrm{UV}$ \\
\hline Goh & 2016 & Singapore & $66(21-85)$ & $\mathrm{R}$ & $142 / 24$ & Asian & $23(0-170)$ & Surgery & 166 & Mixed & 290 & OS/RFS & Reported & UV \\
\hline Ji & 2016 & China & $51(21-79)$ & $\mathrm{R}$ & $285 / 36$ & Asian & NA & Surgery & 321 & Mixed & 115 & OS & Reported & $\mathrm{MV} / \mathrm{UV}$ \\
\hline $\operatorname{Li}(1)$ & 2015 & China & $57(19-86)$ & $\mathrm{R}$ & $211 / 32$ & Asian & $\begin{array}{c}2.7(0.1- \\
44.8)\end{array}$ & Mixed & 243 & Metastatic & 111.23 & OS & Reported & $\mathrm{MV} / \mathrm{UV}$ \\
\hline $\operatorname{Li}(2)$ & 2015 & China & $59.5 \pm 12.1$ & $\mathrm{R}$ & $329 / 85$ & Asian & NA & Mixed & 414 & $\begin{array}{c}\text { Non- } \\
\text { metastatic }\end{array}$ & 87.87 & RFS & Estimated & MV \\
\hline Neofytou & 2014 & UK & NA & $\mathrm{R}$ & $52 / 88$ & Caucasian & $33(1-103)$ & Mixed & 140 & Metastatic & 150 & OS/DFS & Reported & MV/UV \\
\hline Peng & 2015 & China & $50(21-78)$ & $\mathrm{R}$ & $191 / 28$ & Asian & $36.4(3-85.9)$ & Surgery & 219 & Mixed & $\Delta$ PLR 2.875 & OS/RFS & Reported & MV/UV \\
\hline Tian & 2016 & China & $56(26-77)$ & $\mathrm{R}$ & $107 / 15$ & Asian & $22(3-118)$ & Chemotherapy & 122 & Mixed & 96.13 & OS & Reported & $\mathrm{MV} / \mathrm{UVV}$ \\
\hline $\mathrm{Xia}$ & 2015 & China & $49.4(19-71)$ & $\mathrm{R}$ & $308 / 35$ & Asian & $\begin{array}{c}33.7(9.5- \\
132)\end{array}$ & Mixed & 343 & Mixed & 125 & OS/DFS & Estimated & MV \\
\hline Xue & 2015 & China & $53.05 \pm 11.48$ & $\mathrm{R}$ & $258 / 33$ & Asian & 9 & Chemotherapy & 291 & Mixed & 150 & OS & Reported & MV/UV \\
\hline
\end{tabular}

R: retrospective; OS: overall survival; DFS: disease-free survival; RFS: recurrence-free survival; MV: multivariate;

UV: univariate; NA: not available.

Table 2: Methodological assessments of the studies included in the meta-analysis

\begin{tabular}{lccccc}
\hline Author & Global score (\%) & $\begin{array}{c}\text { Scientific } \\
\text { design (/10) }\end{array}$ & $\begin{array}{c}\text { Laboratory } \\
\text { methodology } \\
(/ \mathbf{1 4})\end{array}$ & $\begin{array}{c}\text { Generalizability } \\
(/ \mathbf{1 2})\end{array}$ & $\begin{array}{c}\text { Results } \\
\text { analysis (/8) }\end{array}$ \\
\hline D'Emic & 65.9 & 7 & 6 & 9 & 7 \\
Fan & 72.7 & 7 & 6 & 12 & 7 \\
Goh & 65.9 & 8 & 6 & 8 & 7 \\
Ji & 70.5 & 9 & 6 & 10 & 6 \\
Li(1) & 70.5 & 8 & 4 & 11 & 8 \\
Li(2) & 61.4 & 7 & 6 & 10 & 4 \\
Neofytou & 70.5 & 9 & 6 & 8 & 8 \\
Peng & 68.2 & 7 & 6 & 10 & 7 \\
Tian & 72.7 & 8 & 6 & 10 & 8 \\
Xia & 50.0 & 6 & 6 & 6 & 4 \\
Xue & 75.0 & 9 & 6 & 10 & 8 \\
\hline
\end{tabular}

receiving chemotherapy $(\mathrm{HR}=1.77 ; 95 \% \mathrm{CI}=1.43-2.21$; $\mathrm{P}<0.001)$, surgery $(\mathrm{HR}=2.38 ; 95 \% \mathrm{CI}=1.17-4.84 ; \mathrm{P}=$ $0.02)$, and mixed methods $(\mathrm{HR}=1.40 ; 95 \% \mathrm{CI}=1.01$ $1.92 ; \mathrm{P}=0.04)$. In the subgroup analysis by disease stage, patients with high PLR had significantly worse OS in patients with non-metastatic disease (pooled $\mathrm{HR}=2.68$; $95 \% \mathrm{CI}=1.55-4.63 ; \mathrm{P}<0.001)$ and mixed subgroup $(\mathrm{HR}=1.79 ; 95 \% \mathrm{CI}=1.39-2.29 ; \mathrm{P}<0.001)$. The cutoff values ranged from 87.87 to 290 . We stratified cut-off values into two subgroups: $<150$ and $\geq 150$. Stratification by the cut-off value showed the OS rate was significantly worse in all subgroups. In addition, subgroup analyses suggested that high PLR predicted poor OS in patient with HCC, regardless of the sample size $(<200$ and $\geq 200)$, HR estimation (reported and estimated), analysis method (univariate and multivariate), and ELCWP score ( $<70$ and $\geq 70$ ). 


\section{Disease-free survival/recurrence-free survival}

Five studies comprising 1,282 patients evaluated the association between PLR and DFS/RFS. In comparison with a low PLR, a high PLR was significantly correlated with worse DFS/RFS (HR $=1.82 ; 95 \% \mathrm{CI}=1.56-2.13$; $\mathrm{P}$ $<0.001$; Figure 3$)$, without significant heterogeneity $\left(\mathrm{I}^{2}=\right.$ $17 \% ; \mathrm{P}=0.31)$.

\section{Clinicopathological parameters}

In the meta-analysis, we identified 12 clinical factors to explore the impact of PLR on the clinical features in HCC. Pooled data revealed that a high PLR was significantly related to tumor size ( $>3 \mathrm{~cm}$ vs. $<3$ $\mathrm{cm} ; \mathrm{HR}=1.67,95 \% \mathrm{CI}: 1.11-2.52, \mathrm{P}=0.01)$, TNM stage (III-IV vs. I-II; HR $=2.20,95 \%$ CI: $1.11-4.33, \mathrm{P}=0.02$ ), lymph node metastasis (pos vs. neg; $\mathrm{HR}=1.62,95 \% \mathrm{CI}$ : 1.01-2.60, $\mathrm{P}=0.04$ ), distant metastasis (pos vs. neg; $\mathrm{HR}=$ $2.38,95 \%$ CI: $1.23-4.60, \mathrm{P}=0.01$ ), and vascular invasion (pos vs. neg; $\mathrm{HR}=1.70,95 \% \mathrm{CI}$ : $1.20-2.43, \mathrm{P}=0.003$ ). Whereas no significant association was found with gender (male vs. female), cirrhosis (yes vs. no), AFP ( $>400 \mathrm{ng} / \mathrm{mL}$ vs. $<400 \mathrm{ng} / \mathrm{mL}$ ), Child-Pugh classification (B/C vs. A), differentiation (low vs. moderate/high), tumor number ( $>3$ cm vs. $<3 \mathrm{~cm}$ ), tumor size ( $>5 \mathrm{~cm}$ vs. $<5 \mathrm{~cm}$ ), and tumor distribution (bilobar vs. unilobar). The correlation between PLR expression and clinicopathological parameters of HCC is shown in Table 4.

\section{Sensitivity analysis and publication bias}

Each single study was removed each time to estimate the influence of individual data sets on the combined HR. The results of sensitivity analysis showed that no study had a significant effect on the observed effect size (pooled HR), indicating the robustness of our findings. Evidence of publication bias was observed for OS ( $\mathrm{P}=0.074$ for Begg's test and $\mathrm{P}<0.001$ for Egger's test), while no significant publication bias was detected for DFS/RFS by both the Begg's test $(\mathrm{P}=1.000)$ and the Egger's test $(\mathrm{P}=0.864)$. Using "trim and fill" method, we assessed the impact of this bias and the HR for OS didn't show a shift.

\section{DISCUSSION}

HCC has been shown to be an inflammationinduced cancer [27]. Approximately $80 \%$ of HCC cases are related to chronic HBV or HCV infections [28]. Recently, several clinical studies showed that a high PLR correlates with worse prognosis and clinicopathologic features in patients with HCC [18, 19, 29]. Moreover, Tian et al. found that elevated pretreatment PLR is predictive of poor OS among patients with HBV-related HCC [24]. Similarly, Fan et al. reported that a high PLR correlates significantly with a poor prognosis and metastasis in recurrent HCC patients [17]. PLR has also been shown to correlate with recurrence and survival rates in patients with HCC [29]. These findings suggest PLR could serve as a promising prognostic or therapeutic target for HCC patients. To our knowledge, this is the first meta-analysis investigating the correlation between PLR and survival or clinicopathological features in patients with HCC.

We identified 11 studies involving 2,507 patients that evaluated the clinical relevance and prognostic value of PLR in patients with HCC. This meta-analysis showed that elevated PLR is an unfavorable prognostic factor for OS and DFS/RFS in patients with HCC. Subgroup analyses revealed that the negative prognostic effect of elevated PLR remained substantial despite different sample sizes, cut-off values, treatment methods, HR estimation methods, analysis methods, and ELCWP scores. However, a stratified analysis showed that a high PLR had no prognostic efficiency for OS in Caucasian or metastatic patients. Additionally, when we further analyzed the correlations between pretreatment PLR and clinicopathologic parameters, we found that elevated PLR

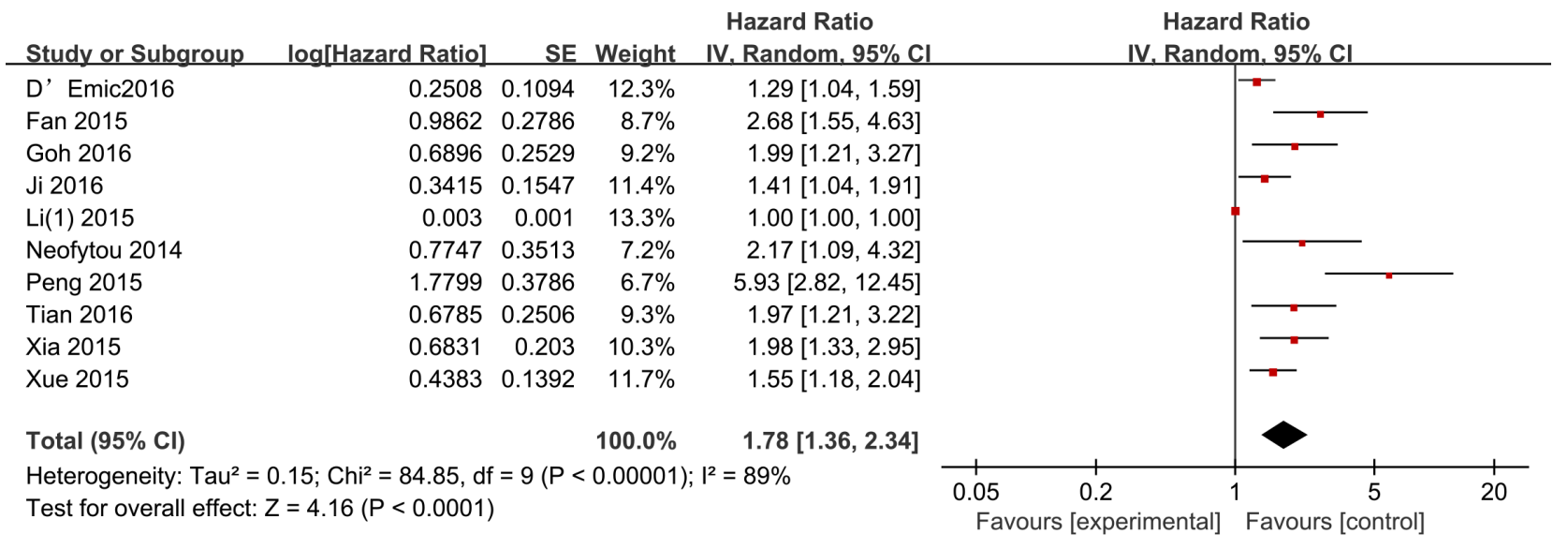

Figure 2: Forest plots for the association between PLR expression and OS. 
Table 3: Pooled hazard ratios (HRs) for OS according to subgroup analyses

\begin{tabular}{|c|c|c|c|c|c|c|c|}
\hline \multirow{2}{*}{ Subgroup } & \multirow{2}{*}{$\begin{array}{l}\text { No. of } \\
\text { studies }\end{array}$} & \multirow{2}{*}{$\begin{array}{c}\text { No. of } \\
\text { patients }\end{array}$} & \multirow{2}{*}{$\begin{array}{l}\text { Effects } \\
\text { model }\end{array}$} & \multirow{2}{*}{ HR $(95 \%$ CI $)$} & \multirow{2}{*}{ P value } & \multicolumn{2}{|c|}{ Heterogeneity } \\
\hline & & & & & & $I^{2}(\%)$ & $\mathbf{P}_{\mathrm{h}}$ \\
\hline Overall & 10 & 2093 & Random & $1.78(1.36,2.34)$ & $<0.001$ & 89 & $<0.001$ \\
\hline \multicolumn{8}{|l|}{ Ethnicity } \\
\hline Asian & 8 & 1837 & Random & $1.88(1.33,2.65)$ & $<0.001$ & 91 & $<0.001$ \\
\hline Caucasian & 2 & 256 & Random & $1.50(0.94,2.40)$ & 0.09 & 51 & 0.15 \\
\hline \multicolumn{8}{|l|}{ Treatment } \\
\hline Chemotherapy & 3 & 545 & Fixed & $1.77(1.43,2.21)$ & $<0.001$ & 40 & 0.19 \\
\hline Surgery & 3 & 706 & Random & $2.38(1.17,4.84)$ & 0.02 & 84 & 0.002 \\
\hline Mixed & 6 & 842 & Random & $1.40(1.01,1.92)$ & 0.04 & 86 & $<0.001$ \\
\hline \multicolumn{8}{|l|}{ Sample size } \\
\hline$<200$ & 5 & 676 & Random & $1.85(1.35,2.53)$ & $<0.001$ & 58 & 0.05 \\
\hline$\geq 200$ & 5 & 1417 & Random & $1.71(1.14,2.57)$ & 0.009 & 92 & $<0.001$ \\
\hline \multicolumn{8}{|l|}{ Disease stage } \\
\hline Non-metastatic & 1 & 132 & - & $2.68(1.55,4.63)$ & $<0.001$ & - & - \\
\hline $\begin{array}{l}\text { Mixed (non-metastatic } \\
\& \text { metastatic) }\end{array}$ & 7 & 1578 & Random & $1.79(1.39,2.29)$ & $<0.001$ & 69 & 0.004 \\
\hline Metastatic & 2 & 383 & Random & $1.36(0.65,2.85)$ & 0.41 & 79 & 0.03 \\
\hline \multicolumn{8}{|l|}{ Cut-off for PLR } \\
\hline$<150$ & 6 & 1380 & Random & $1.96(1.25,3.06)$ & 0.003 & 91 & $<0.001$ \\
\hline$\geq 150$ & 4 & 713 & Fixed & $1.46(1.25,1.71)$ & $<0.001$ & 31 & 0.23 \\
\hline \multicolumn{8}{|l|}{ HR estimation } \\
\hline Reported & 9 & 1750 & Random & $1.76(1.32,2.33)$ & $<0.001$ & 89 & $<0.001$ \\
\hline Estimated & 1 & 343 & - & $1.98(1.33,2.95)$ & $<0.001$ & - & - \\
\hline \multicolumn{8}{|l|}{ Analysis method } \\
\hline Univariate & 1 & 166 & - & $1.99(1.21,3.27)$ & 0.006 & - & - \\
\hline Multivariate & 9 & 1927 & Random & $1.76(1.33,2.34)$ & $<0.001$ & 90 & $<0.001$ \\
\hline \multicolumn{8}{|l|}{ ELCWP score } \\
\hline$<70$ & 4 & 844 & Random & $2.14(1.29,3.56)$ & 0.003 & 83 & $<0.001$ \\
\hline$\geq 70$ & 6 & 1249 & Random & $1.61(1.15,2.24)$ & 0.005 & 87 & $<0.001$ \\
\hline
\end{tabular}

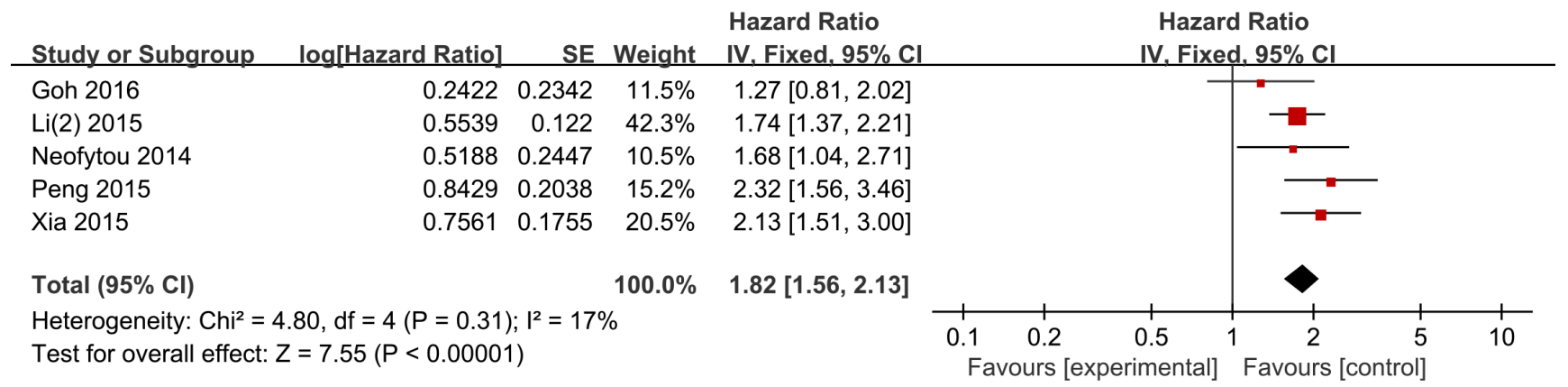

Figure 3: Forest plots for the association between PLR expression and DFS/RFS. 
Table 4: Meta-analysis of the association between PLR and clinicopathological features of HCC

\begin{tabular}{lcccccc}
\hline Characteristics & $\begin{array}{c}\text { No. of } \\
\text { studies }\end{array}$ & $\begin{array}{c}\text { No. of } \\
\text { patients }\end{array}$ & OR (95\% CI) & p & Heterogeneity \\
\hline Gender (male vs. female) & 9 & 2070 & $0.79(0.61,1.01)$ & 0.06 & 0 & 0.57 \\
Cirrhosis (yes vs. no) & 4 & 1090 & $1.88(0.22,16.26)$ & 0.57 & 97 & $<0.001$ \\
AFP(>400 ng/mL vs. $<400 \mathrm{ng} / \mathrm{mL})$ & 4 & 764 & $1.13(0.83,1.52)$ & 0.44 & 34 & 0.21 \\
Child-Pugh classification (B/C vs. A) & 4 & 911 & $0.94(0.62,1.42)$ & 0.76 & 46 & 0.14 \\
Differentiation ( low vs. moderate/high) & 3 & 976 & $1.01(0.42,2.42)$ & 0.99 & 72 & 0.03 \\
Tumor number (> 3 cm vs. $<3$ cm) & 3 & 615 & $0.45(0.14,1.47)$ & 0.19 & 87 & $<0.001$ \\
Tumor size (> 3 cm vs. $<3$ cm) & 3 & 473 & $1.67(1.11,2.52)$ & 0.01 & 26 & 0.26 \\
Tumor size (> 5 cm vs. $<5$ cm) & 2 & 483 & $2.07(0.29,14.62)$ & 0.46 & 93 & $<0.001$ \\
Tumor distribution (bilobar vs. unilobar) & 2 & 306 & $1.17(0.68,2.03)$ & 0.56 & 26 & 0.24 \\
TNM stage (III-IV vs. I-II) & 3 & 531 & $2.20(1.11,4.33)$ & 0.02 & 61 & 0.07 \\
Lymph node metastasis (pos vs. neg) & 2 & 365 & $1.62(1.01,2.60)$ & 0.04 & 0 & 0.83 \\
Distant metastasis (pos vs. neg) & 1 & 243 & $2.38(1.23,4.60)$ & 0.01 & - & - \\
Vascular invasion (pos vs. neg) & 4 & 860 & $1.70(1.20,2.43)$ & 0.003 & 0 & 0.41 \\
\hline
\end{tabular}

was linked with tumor size $>3 \mathrm{~cm}$, TNM stage, lymph node metastasis, distant metastasis, and vascular invasion.

The mechanisms responsible for the association between high PLR and poor outcome in HCC remain unclear. However, mounting evidence suggests that systemic inflammation plays an important role in tumor initiation and progression by contributing to genomic instability, genetic mutations, cancer cell proliferation, angiogenesis, and hematogenous metastasis $[13,30]$. Cancer-related inflammation can suppress antitumor immunity by recruiting immunosuppressive cells such as myeloid-derived suppressor cells and regulatory $\mathrm{T}$ cells, resulting in tumor progression [31,32].

It has been suggested that there is cross-talk between the inflammatory response and tumor progression $[5,13$, 33]. It is now generally accepted that platelets bind VEGF, PDGF, FGF, and TGF- $\beta$ family proteins, enabling platelets to act as a reservoir for secreted growth factors that increase tumor angiogenesis, cell proliferation, migration, and metastasis [34-36]. Tumor-infiltrating lymphocytes (TILs) are important immune cells found within tumors and are responsible for antitumor immune responses [37]. High numbers of TILs correlate with favorable clinical outcomes [38, 39]. In HCC patients, high levels of tumorinfiltrating CD4+ $\mathrm{T}$ lymphocytes are associated with a lower recurrence rate and better prognosis [40]. This suggests PLR combined with the effects of platelets and lymphocytes may be predictive of prognosis in patients with HCC.

This meta-analysis has several limitations. First, significant heterogeneity was found among studies. However, subgroup analyses showed that the heterogeneity diminished or disappeared in patients receiving chemotherapy, and the cut-off for PLR $\geq 150$. Moreover, the stability of our results was confirmed by sensitivity analysis. Second, the cut-off value for PLR differed among the studies. This may be a significant contributor to the heterogeneity. Third, publication bias was detected for OS. As we know, studies with negative results are less likely to be published than those with positive results. Additionally, only published articles were included, and they were all written in English. Therefore, the summary statistics obtained may not approximate the actual average. However, using the "Trim and Fill" method to evaluate this bias, the pooled effect size remained significant. This indicates the reliability of our results. Fourth, HRs and their 95\% CIs were extracted from univariable analyses in only one study and estimated from Kaplan-Meier survival curves in two studies. Thus, the prognostic value of PLR may be overestimated.

In conclusion, our meta-analysis confirms that an elevated pretreatment PLR is significantly associated with poor survival in conjunction with advanced tumor stage and positive metastasis in HCC patients. This suggests pretreatment PLR could provide essential information that informs prognosis and treatment decisions for patients HCC.

\section{MATERIALS AND METHODS}

\section{Search strategies}

A comprehensive search of MEDLINE, EMBASE, and Cochrane databases from the inception to July 
2016 was performed. The following MeSH terms and text words were used in combination: "hepatocellular carcinoma" or "HCC" or "liver cancer" or "liver tumor" or "liver neoplasms" or "liver cell carcinoma", "platelet to lymphocyte ratio" or "PLR" or "platelet lymphocyte ratio" or "platelet-lymphocyte ratio", "prognostic" or "prognosis" or "survival" or "recurrence" or "outcome". In addition, the references of eligible studies, pertinent reviews, and meta-analyses in this field were screened.

\section{Study selection}

The criteria for inclusion were listed as follows: (1) the diagnosis of HCC was pathologically confirmed. (2) assessing the prognostic value of pretreatment PLR on OS, DFS and/or RFS; (3) reporting a sufficient information to estimate the hazard ratio (HR) and 95\% confidence interval (CI); (4) reporting a dichotomous cut-off value for PLR; and (5) original high-quality English articles. The exclusion criteria were: (1) abstract, reviews, conference, case reports, and expert opinion; (2) reporting PLR only as a continuous variable; (3) lacking essential information for calculating an HR and 95\% CI; and (4) overlapping or duplicate data.

\section{Data extraction}

The following information was captured using data abstraction forms:

first author's name, year of publication, study design, country, ethnicity, patient ages and genders, number of patients, disease stage, treatment, follow-up, cut-off value, outcome measures (HRs for OS, DFS, or RFS, as well as their 95\% CIs), survival analysis methods, and clinicopathological features. HRs were directly extracted from multivariate or univariate analyses or estimated from Kaplan-Meier survival curves independently by two reviewers and any discrepancies were resolved a third reviewer.

\section{Quality assessment}

The quality of each study was evaluated in accordance with the revised ELCWP scoring scale described by Steel et al. [41]. Each item was assessed using an ordinal scale (possible values: 2, 1, 0). The overall score include the following four categories: (1) scientific design: 0-10; (2) laboratory methodology: 0-14; (3) generalizability: 0-12; (4) results analysis: 0-8. The total scores ranged from 0 to 44 . The final scores are expressed as percentages, with a higher scores reflecting a better methodological quality.

\section{Statistical analyses}

The meta-analysis was conducted by RevMan 5.3 software (Cochrane Collaboration, Copenhagen, Denmark) and STATA 12.0 (College Station, TX, USA). HRs and their $95 \%$ CIs were searched in the original articles or extrapolated using methods described by Tierney and Parmar [42, 43]. The associations between PLR and clinicopathologic features were expressed as odds ratios (ORs) and its $95 \%$ CIs. Statistical heterogeneity among eligible studies was estimated using Cochrane's Q statistic and $\mathrm{I}^{2}$ statistic [44]. A p-value $<0.1$ for the Q-test or $\mathrm{I}^{2}$ $>50 \%$ was considered statistically significant. When there was no statistically significant heterogeneity, we used the fixed-effects model for pooling the results; otherwise, the random-effects model was applied. Subgroup analyses stratified by ethnicity, treatment, sample size, disease stage, HR estimation, analysis method, ELCWP score, and the cut-off value of PLR. In order to evaluate the robustness of conclusions, sensitivity analysis was performed by excluding single study at a time from the meta-analysis to explore its influence on the pooled HR for OS. Publication bias was evaluated using Begg's funnel plots and Egger's tests. When publication bias was identified, we used the "Trim and Fill" method to re-estimate a corrected effect size after adjustment for publication bias [45]. P $<0.05$ was defined as statistically significant.

\section{ACKNOWLEDGMENTS}

The authors gratefully acknowledge the reviewers for their helpful comments on this paper.

\section{CONFLICTS OF INTEREST}

The authors declare that there are no conflicts of interest.

\section{FUNDING}

No funding source.

\section{REFERENCES}

1. Torre LA, Bray F, Siegel RL, Ferlay J, Lortet-Tieulent J, Jemal A. Global cancer statistics, 2012. CA Cancer J Clin. 2015; 65:87-108. doi: 10.3322/caac.21262.

2. Forner A, Llovet JM, Bruix J. Hepatocellular carcinoma. Lancet. 2012; 379:1245-55. doi: 10.1016/ s0140-6736(11)61347-0.

3. Thomas MB, Jaffe D, Choti MM, Belghiti J, Curley S, Fong Y, Gores G, Kerlan R, Merle P, O'Neil B, Poon R, Schwartz L, Tepper J, et al. Hepatocellular carcinoma: consensus recommendations of the National Cancer Institute Clinical Trials Planning Meeting. J Clin Oncol. 2010; 28:3994-4005. doi: $10.1200 /$ jco.2010.28.7805. 
4. Bruix J, Sherman M. Management of hepatocellular carcinoma: an update. Hepatology. 2011; 53:1020-2. doi: 10.1002/hep.24199.

5. Grivennikov SI, Greten FR, Karin M. Immunity, inflammation, and cancer. Cell. 2010; 140:883-99. doi: 10.1016/j.cell.2010.01.025.

6. Facciorusso A, Prete VD, Antonino M, Neve V, Crucinio $\mathrm{N}$, Leo AD, Carr BI, Barone M. Serum ferritin as a new prognostic factor in hepatocellular carcinoma patients treated with radiofrequency ablation. J Gastroenterol Hepatol. 2014; 29:1905-10. doi: 10.1111/jgh.12618.

7. Lee S, Song A, Eo W. Serum Ferritin as a Prognostic Biomarker for Survival in Relapsed or Refractory Metastatic Colorectal Cancer. J Cancer. 2016; 7:957-64. doi: 10.7150/jca.14797.

8. Chen Y, Chen K, Xiao X, Nie Y, Qu S, Gong C, Su F, Song E. Pretreatment neutrophil-to-lymphocyte ratio is correlated with response to neoadjuvant chemotherapy as an independent prognostic indicator in breast cancer patients: a retrospective study. BMC Cancer. 2016; 16:320. doi: 10.1186/s12885-016-2352-8.

9. Wu SJ, Lin YX, Ye H, Li FY, Xiong XZ, Cheng NS. Lymphocyte to monocyte ratio and prognostic nutritional index predict survival outcomes of hepatitis B virusassociated hepatocellular carcinoma patients after curative hepatectomy. J Surg Oncol. 2016; 114:202-10. doi: 10.1002/ jso. 24297 .

10. Gu X, Gao XS, Cui M, Xie M, Peng C, Bai Y, Guo W, Han L, Gu X, Xiong W. Clinicopathological and prognostic significance of platelet to lymphocyte ratio in patients with gastric cancer. Oncotarget. 2016; 7:49878-49887. doi: 10.18632/oncotarget.10490.

11. Egan K, Crowley D, Smyth P, O'Toole S, Spillane C, Martin C, Gallagher M, Canney A, Norris L, Conlon N, McEvoy L, Ffrench B, Stordal B, et al. Platelet adhesion and degranulation induce pro-survival and pro-angiogenic signalling in ovarian cancer cells. PLoS One. 2011; 6:e26125. doi: 10.1371/journal.pone.0026125.

12. Labelle M, Begum S, Hynes RO. Platelets guide the formation of early metastatic niches. Proc Natl Acad Sci U S A. 2014; 111:E3053-61. doi: 10.1073/pnas.1411082111.

13. Mantovani A, Allavena P, Sica A, Balkwill F. Cancer-related inflammation. Nature. 2008; 454:436-44. doi: 10.1038/ nature07205.

14. Asano Y, Kashiwagi S, Onoda N, Noda S, Kawajiri H, Takashima T, Ohsawa M, Kitagawa S, Hirakawa K. Platelet-Lymphocyte Ratio as a Useful Predictor of the Therapeutic Effect of Neoadjuvant Chemotherapy in Breast Cancer. PLoS One. 2016; 11:e0153459. doi: 10.1371/ journal.pone.0153459.

15. You J, Zhu GQ, Xie L, Liu WY, Shi L, Wang OC, Huang $\mathrm{ZH}$, Braddock M, Guo GL, Zheng MH. Preoperative platelet to lymphocyte ratio is a valuable prognostic biomarker in patients with colorectal cancer. Oncotarget. 2016; 7:25516-27. doi: 10.18632/oncotarget.8334.

16. D'Emic N, Engelman A, Molitoris J, Hanlon A, Sharma NK, Moeslein FM, Chuong MD. Prognostic significance of neutrophil-lymphocyte ratio and platelet-lymphocyte ratio in patients treated with selective internal radiation therapy. Journal of Gastrointestinal Oncology. 2016; 7:269-77.

17. Fan W, Zhang Y, Wang Y, Yao X, Yang J, Li J. Neutrophil-tolymphocyte and platelet-to-lymphocyte ratios as predictors of survival and metastasis for recurrent hepatocellular carcinoma after transarterial chemoembolization. PLoS ONE. 2015; 10:e0119312.

18. Goh BK, Kam JH, Lee SY, Chan CY, Allen JC, Jeyaraj P, Cheow PC, Chow PK, Ooi LL, Chung AY. Significance of neutrophil-to-lymphocyte ratio, platelet-to-lymphocyte ratio and prognostic nutrition index as preoperative predictors of early mortality after liver resection for huge $(>/=10 \mathrm{~cm})$ hepatocellular carcinoma. J Surg Oncol. 2016; 113:621-7. doi: $10.1002 /$ jso. 24197.

19. Ji F, Liang Y, Fu SJ, Guo ZY, Shu M, Shen SL, Li SQ, Peng BG, Liang LJ, Hua YP. A novel and accurate predictor of survival for patients with hepatocellular carcinoma after surgical resection: the neutrophil to lymphocyte ratio (NLR) combined with the aspartate aminotransferase/platelet count ratio index (APRI). BMC Cancer. 2016; 16:137.

20. Li X, Chen ZH, Xing YF, Wang TT, Wu DH, Wen JY, Chen J, Lin Q, Dong M, Wei L, Ruan DY, Lin ZX, Wu XY, et al. Platelet-to-lymphocyte ratio acts as a prognostic factor for patients with advanced hepatocellular carcinoma. Tumour Biol. 2015; 36:2263-9. doi: 10.1007/s13277-014-2833-9.

21. Li X, Han Z, Cheng Z, Yu J, Yu X, Liang P. Clinical significance of preoperative platelet-to-lymphocyte ratio in recurrent hepatocellular carcinoma after thermal ablation: A retrospective analysis. Int J Hyperthermia. 2015; 31:758-63. doi: 10.3109/02656736.2015.1068958.

22. Neofytou K, Smyth EC, Giakoustidis A, Khan AZ, Cunningham D, Mudan S. Elevated platelet to lymphocyte ratio predicts poor prognosis after hepatectomy for liveronly colorectal metastases, and it is superior to neutrophil to lymphocyte ratio as an adverse prognostic factor. Med Oncol. 2014; 31:239. doi: 10.1007/s12032-014-0239-6.

23. Peng W, Li C, Zhu WJ, Wen TF, Yan LN, Li B, Wang WT, Yang JY. Prognostic value of the platelet to lymphocyte ratio change in liver cancer. J Surg Res. 2015; 194:464-70. doi: 10.1016/j.jss.2014.12.021.

24. Tian XC, Liu XL, Zeng FR, Chen Z, Wu DH. Plateletto-lymphocyte ratio acts as an independent risk factor for patients with hepatitis B virus-related hepatocellular carcinoma who received transarterial chemoembolization. Eur Rev Med Pharmacol Sci. 2016; 20:2302-9.

25. Xia W, Ke Q, Wang Y, Wang W, Zhang M, Shen Y, Wu J, $\mathrm{Xu}$ X, Zheng S. Predictive value of pre-transplant platelet to lymphocyte ratio for hepatocellular carcinoma recurrence after liver transplantation. World J Surg Oncol. 2015; 13:60. doi: 10.1186/s12957-015-0472-2. 
26. Xue TC, Jia QA, Ge NL, Zhang BH, Wang YH, Ren ZG, Ye SL. The platelet-to-lymphocyte ratio predicts poor survival in patients with huge hepatocellular carcinoma that received transarterial chemoembolization. Tumour Biol. 2015; 36:6045-51. doi: 10.1007/s13277-015-3281-x.

27. Matsuzaki K, Murata M, Yoshida K, Sekimoto G, Uemura Y, Sakaida N, Kaibori M, Kamiyama Y, Nishizawa M, Fujisawa J, Okazaki K, Seki T. Chronic inflammation associated with hepatitis $\mathrm{C}$ virus infection perturbs hepatic transforming growth factor beta signaling, promoting cirrhosis and hepatocellular carcinoma. Hepatology. 2007; 46:48-57. doi: 10.1002/hep.21672.

28. Perz JF, Armstrong GL, Farrington LA, Hutin YJ, Bell BP. The contributions of hepatitis $B$ virus and hepatitis $C$ virus infections to cirrhosis and primary liver cancer worldwide. J Hepatol. 2006; 45:529-38. doi: 10.1016/j.jhep.2006.05.013.

29. Lai Q, Castro Santa E, Rico Juri JM, Pinheiro RS, Lerut J. Neutrophil and platelet-to-lymphocyte ratio as new predictors of dropout and recurrence after liver transplantation for hepatocellular cancer. Transpl Int. 2014; 27:32-41. doi: 10.1111/tri.12191.

30. Sideras K, Kwekkeboom J. Cancer inflammation and inflammatory biomarkers: can neutrophil, lymphocyte, and platelet counts represent the complexity of the immune system? Transpl Int. 2014; 27:28-31. doi: 10.1111/tri.12229.

31. Brimnes MK, Vangsted AJ, Knudsen LM, Gimsing P, Gang AO, Johnsen HE, Svane IM. Increased level of both CD4+FOXP3+ regulatory T cells and CD14+HLA-DR(-)/ low myeloid-derived suppressor cells and decreased level of dendritic cells in patients with multiple myeloma. Scand J Immunol. 2010; 72:540-7. doi: 10.1111/j.1365-3083.2010.02463.x.

32. Wang G, Lu X, Dey P, Deng P, Wu CC, Jiang S, Fang Z, Zhao K, Konaparthi R, Hua S, Zhang J, Li-Ning-Tapia EM, Kapoor A, et al. Targeting YAP-Dependent MDSC Infiltration Impairs Tumor Progression. Cancer Discov. 2016; 6:80-95. doi: 10.1158/2159-8290.cd-15-0224.

33. Palumbo JS, Degen JL. Mechanisms coupling the hemostatic system to colitis-associated cancer. Thromb Res. 2010; 125 Suppl 2:S39-43. doi: 10.1016/ s0049-3848(10)70011-6.

34. Wakefield LM, Smith DM, Flanders KC, Sporn MB. Latent transforming growth factor-beta from human platelets. A high molecular weight complex containing precursor sequences. J Biol Chem. 1988; 263:7646-54.

35. Gay LJ, Felding-Habermann B. Contribution of platelets to tumour metastasis. Nat Rev Cancer. 2011; 11:123-34. doi: $10.1038 / \mathrm{nrc} 3004$.
36. Banks RE, Forbes MA, Kinsey SE, Stanley A, Ingham E, Walters C, Selby PJ. Release of the angiogenic cytokine vascular endothelial growth factor (VEGF) from platelets: significance for VEGF measurements and cancer biology. Br J Cancer. 1998; 77:956-64.

37. Man YG, Stojadinovic A, Mason J, Avital I, Bilchik A, Bruecher B, Protic M, Nissan A, Izadjoo M, Zhang X, Jewett A. Tumor-infiltrating immune cells promoting tumor invasion and metastasis: existing theories. J Cancer. 2013; 4:84-95. doi: 10.7150/jca.5482.

38. Fortes C, Mastroeni S, Mannooranparampil TJ, Passarelli F, Zappala A, Annessi G, Marino C, Caggiati A, Russo N, Michelozzi P. Tumor-infiltrating lymphocytes predict cutaneous melanoma survival. Melanoma Res. 2015; 25:306-11. doi: 10.1097/cmr.0000000000000164.

39. Gooden MJ, de Bock GH, Leffers N, Daemen T, Nijman HW. The prognostic influence of tumour-infiltrating lymphocytes in cancer: a systematic review with metaanalysis. Br J Cancer. 2011; 105:93-103. doi: 10.1038/ bjc.2011.189.

40. Wada Y, Nakashima O, Kutami R, Yamamoto O, Kojiro M. Clinicopathological study on hepatocellular carcinoma with lymphocytic infiltration. Hepatology. 1998; 27:407-14. doi: 10.1002/hep.510270214.

41. Steels E, Paesmans M, Berghmans T, Branle F, Lemaitre F, Mascaux C, Meert AP, Vallot F, Lafitte JJ, Sculier JP. Role of p53 as a prognostic factor for survival in lung cancer: a systematic review of the literature with a meta-analysis. Eur Respir J. 2001; 18:705-19.

42. Parmar MK, Torri V, Stewart L. Extracting summary statistics to perform meta-analyses of the published literature for survival endpoints. Stat Med. 1998; 17:2815-34.

43. Tierney JF, Stewart LA, Ghersi D, Burdett S, Sydes MR. Practical methods for incorporating summary time-toevent data into meta-analysis. Trials. 2007; 8:16. doi: 10.1186/1745-6215-8-16.

44. Higgins J, Thompson S, Deeks J, Altman D. Statistical heterogeneity in systematic reviews of clinical trials: a critical appraisal of guidelines and practice. J Health Serv Res Policy. 2002; 7:51-61.

45. Duval S, Tweedie R. Trim and fill: A simple funnel-plotbased method of testing and adjusting for publication bias in meta-analysis. Biometrics. 2000; 56:455-63. 